\title{
Behavioural and energetic consequences of competition among three overwintering swan (Cygnus spp.) species
}

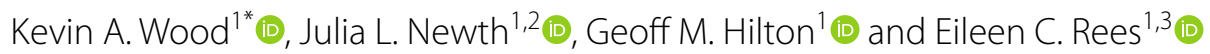

\begin{abstract}
Background: Winter numbers of the northwest European population of Bewick's Swans (Cygnus columbianus bewickii) declined recently by c. 40\%. During the same period, numbers of two sympatric and ecologically-similar congeners, the Mute Swan (Cygnus olor) and Whooper Swan (Cygnus cygnus) showed increases or stability. It has been suggested that these opposing population trends could have a causal relationship, as Mute and Whooper Swans are larger and competitively dominant to Bewick's Swans in foraging situations. If so, effects of competition of Mute and Whooper Swans on Bewick's Swans should be detectable as measurable impacts on behaviour and energetics.

Methods: Here, we studied the diurnal behaviour and energetics of 1083 focal adults and first-winter juveniles ("cygnets") of the three swan species on their winter grounds in eastern England. We analysed video recordings to derive time-activity budgets and these, together with estimates of energy gain and expenditure, were analysed to determine whether individual Bewick's Swans altered the time spent on key behaviours when sharing feeding habitat with other swan species, and any consequences for their energy expenditure and net energy gain.
\end{abstract}

Results: All three swan species spent a small proportion of their total time (0.011) on aggressive interactions, and these were predominantly intraspecific ( $\geq 0.714$ ). Mixed-effects models indicated that sharing feeding habitat with higher densities of Mute and Whooper Swans increased the likelihood of engaging in aggression for cygnet Bewick's Swans, but not for adults. Higher levels of interspecific competition decreased the time spent by Bewick's Swan cygnets on foraging, whilst adults showed the opposite pattern. When among low densities of conspecifics (<c. 200 individuals $/ \mathrm{km}^{2}$ ), individual Bewick's Swans spent more time on vigilance in the presence of higher densities of Mute and Whooper Swans, whilst individuals within higher density Bewick's Swan flocks showed the opposite pattern. Crucially, we found no evidence that greater numbers of interspecific competitors affected the net energy gain of either adult or cygnet Bewick's Swans.

Conclusions: We found no evidence that Bewick's Swan net energy gain was affected by sharing agricultural feeding habitat with larger congeners during winter. This was despite some impacts on the aggression, foraging and vigilance behaviours of Bewick's Swans, especially among cygnets. It is unlikely therefore that competition between Bewick's Swans and either Mute or Whooper Swans at arable sites in winter has contributed to the observed decline in Bewick's Swan numbers. Further research is needed, however, to test for competition in other parts of the flyway, including migratory stopover sites and breeding areas.

*Correspondence: kevin.wood@wwt.org.uk

${ }^{1}$ Wildfowl \& Wetlands Trust, Slimbridge, Gloucestershire GL2 7BT, United Kingdom

Full list of author information is available at the end of the article permits use, sharing, adaptation, distribution and reproduction in any medium or format, as long as you give appropriate credit to the original author(s) and the source, provide a link to the Creative Commons licence, and indicate if changes were made. The images or other third party material in this article are included in the article's Creative Commons licence, unless indicated otherwise in a credit line to the material. If material is not included in the article's Creative Commons licence and your intended use is not permitted by statutory regulation or exceeds the permitted use, you will need to obtain permission directly from the copyright holder. To view a copy of this licence, visit http://creativecommons.org/licenses/by/4.0/. The Creative Commons Public Domain Dedication waiver (http://creativeco mmons.org/publicdomain/zero/1.0/) applies to the data made available in this article, unless otherwise stated in a credit line to the data. 
Keywords: Avian behaviour, Energy expenditure, Ethology, Interference competition, Interspecific interactions, Time activity budgets, Video observations

\section{Background}

The conservation of avian abundance and diversity represents a major global endeavour, requiring accurate information on the causes of population declines (Kirby et al. 2008). In recent decades, the northwest European population of Bewick's Swans (Cygnus columbianus bewickii) has become a growing conservation concern. Repeated censuses have revealed that numbers wintering in northwest Europe have declined by $39.4 \%$ from a peak of 29,780 individuals in January 1995 , to 18,057 in January 2010, with only a slight recovery to 20,149 in January 2015, and as a result the Bewick's Swan has been classified as Endangered in Europe (BirdLife International 2015; Beekman et al. 2019). To date, the demographic and environmental causes of this population decline have not been resolved fully (Wood et al. 2018; Nuijten et al. 2020a). To help inform conservation efforts, there is a need for further research to assess the impacts that threats to Bewick's Swans might have on swan numbers.

The observed decline in Bewick's Swan numbers was in contrast to many other populations of large herbivorous waterbirds in Europe, which have shown stable or increasing population trends since the Bewick's Swan population peaked in the mid-1990s (Rees et al. 2019). These include two congeners of the Bewick's Swan that are also native to Europe: the Mute Swan (Cygnus olor), which is largely sedentary throughout northwest Europe, and the two populations of migratory Whooper Swan (Cygnus cygnus), one of which breeds in Iceland and winters in the UK and Ireland, while the other breeds in northwest Russia and Fennoscandia, and winters in mainland northwest Europe (Rees et al. 2019). Mute Swan numbers across Europe have shown regional variation, but in almost all regions have either increased or have remained stable since the mid-1990s (Rees et al. 2019; Wood et al. 2019a). Whooper Swan numbers have more than doubled since 1995 (Hall et al. 2016; Laubek et al. 2019).

Both Whooper Swans and Mute Swans show considerable overlap with Bewick's Swans in their use of winter habitat in northwest Europe, with all three species feeding on agricultural crops and frequently associating in mixed species flocks (Rees et al. 1997). As the three swan species exploit the same food resources within the same habitats, the potential for competition amongst the three species exists. Observations have indicated that the larger Mute and Whooper Swans are dominant over the smaller Bewick's Swans in behavioural interactions (Black and Rees 1984; Wood et al. 2020). In a study of all three swan species feeding on grain provided at a lake during winter, Black and Rees (1984) reported that Whooper Swans could displace both Bewick's and Mute Swans from feeding locations. Mute and Whooper Swans could therefore make winter feeding areas less attractive to Bewick's Swans through interference and depletion competition which reduced their rates of energy gain. There are potential fitness consequences to such competition, as for capital breeders such as swans, the energy and body reserves required to breed successfully is gained during the preceding winter (Drent et al. 2006) and at staging sites during migration (Nolet and Drent 1998). Competition at feeding sites therefore has been suggested as a possible contributory factor in the decline of the Bewick's Swan population (Nagy et al. 2012; Ponting 2014), but there have been no empirical tests of this hypothesis since the onset of the decline in Bewick's Swan numbers. Where the three swan species associate in mixed species flocks, any such effects of competition of Mute and Whooper Swans on Bewick's Swans should be detectable as measurable differences in behaviour (e.g. more time spent in aggressive interactions) and energetics (e.g. reduced net energy gain) (Amat 1990). Such an assessment would need to account for variables which might confound any effects of interspecific competition, such as the density of intraspecific competitors; a study of interference competition among Bewick's Swans by Gyimesi et al. (2010) found that individuals suffered progressively reduced food intake rates at greater competitor densities. It is not known, however, whether Bewick's Swans show similar behavioural and energetic responses to rising conspecific and heterospecific competitor densities, or whether the species identity of the surrounding individuals influences those responses.

In this study we assessed the behavioural and energetic consequences for the three swan species where they shared diurnal feeding habitat. Our study had two key objectives. Given that empirical data on interactions amongst overwintering swans are limited, our first objective was to quantify the time spent engaged in aggressive behaviours with conspecifics and heterospecifics. Our second objective was to test whether the behaviour or energetics of swans were altered by the presence of other swan species. 


\section{Methods}

\section{Study system}

Agricultural land in lowland regions of northwest Europe represents important winter habitat for Bewick's, Mute, and Whooper Swans (Owen and Cadbury 1975; Rees et al. 1997; Davis et al. 2014). Our study focused on the area surrounding the Ouse Washes $\left(52^{\circ} 31^{\prime} \mathrm{N}, 0^{\circ} 16^{\prime} \mathrm{E}\right)$ in eastern England; an expanse of former wetland, now drained for agriculture, which features a mosaic of predominantly arable fields and drainage ditches (Nisbet 1955; Thomas et al. 1981). This area supports internationally important numbers of Bewick's and Whooper Swans, as well as nationally important numbers of Mute Swans (Frost et al. 2019). In recognition of their importance for swans and other wildlife, the Ouse Washes has been designated as a Special Protection Area (SPA) under the European Union Birds Directive, as a Ramsar Site under the Convention on Wetlands, and as a Site of Special Scientific Interest (SSSI) under the UK's Wildlife and Countryside Act 1981. However, trends in the numbers of swans using the Ouse Washes winter grounds show marked differences among the three species, with each species showing minimum and maximum counts in different years (Fig. 1). Peak counts of Bewick's Swans have declined over recent winters, from 7491 in 2004/05 to a recent minimum of 1073 in 2013/14, whilst Whooper Swan numbers rose from 4397 in 2004/05 to a high of 8016 in 2015/16 (Fig. 1). Mute Swans have also shown a recent localised decline in numbers from 1151 in 2007/08 to 287 in $2017 / 18$ (Fig. 1), although their national numbers within Britain were stable over this period (Wood et al. 2019a).

Historically, swan species spent some time feeding on flooded grasslands within the Ouse Washes themselves

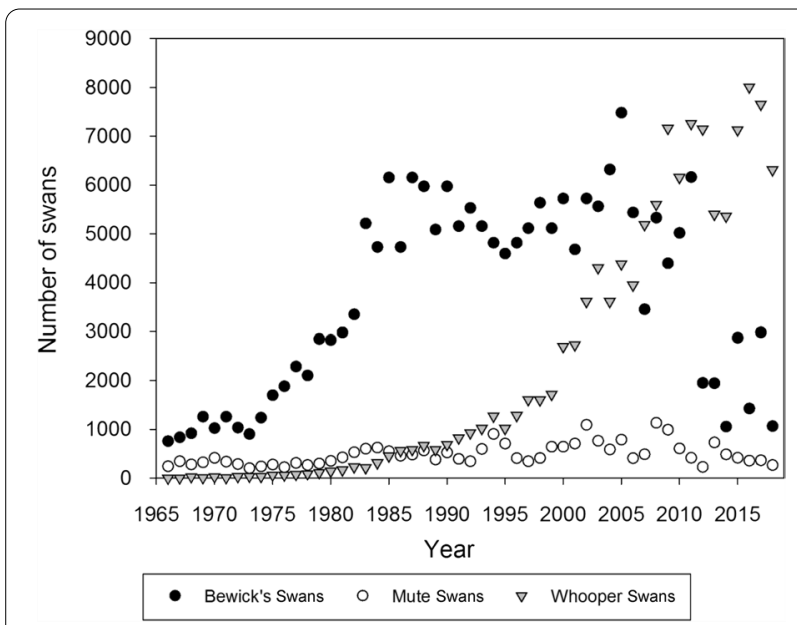

Fig. 1 The long-term trends in the peak numbers of Bewick's, Mute, and Whooper Swans counted on the Ouse Washes as part of the Wetland Bird Survey (WeBS) monitoring programme (Frost et al. 2019)
(Nisbet 1955; Owen and Cadbury 1975), but in recent decades the swans have switched to feed on arable crops almost exclusively, with $<1 \%$ of individuals observed using pastures (Wood et al. 2019c). Overwintering swans feed on arable crops in the fields during the day, and return to the seasonally flooded Ouse Washes to roost (Ponting 2014; Wood et al. 2019c). All three swan species excavate and consume partially-buried post-harvest remains of root crops including Sugar Beet (Beta vulgaris) and Potatoes (Solanum tuberosum), along with some Maize (Zea mays), which are sown in spring for harvest during autumn and early winter (Rees 2006; Wood et al. 2019c). All three swan species graze on the above-ground biomass of cereals and brassicas such as Wheat (Triticum aestivum) or Oilseed Rape (Brassica napus), which are sown in the fields during autumn and early winter (Rees 2006; Wood et al. 2019c).

\section{Data collection}

Video footage of adults and cygnets of all three swan species was obtained during October-March inclusive between winters 2015/16 and 2017/18 (Additional file 1: Table S1). Each month, an area within $15 \mathrm{~km}$ of the Ouse Washes was surveyed for swans over a three-day period, based on the area known to have been used by the swans in previous winters (Ponting 2014; Wood et al. 2019c). The numbers of swans using the study area over a threeday period was considered to be relatively stable, especially given its position on the far edge of the flyways of both Bewick's and Whooper Swans (Brazil 2003; Rees 2006). Moreover, different swan species have been shown to exhibit the same seasonal pattern of habitat use, with post-harvest remains of root crops preferred in early winter, and early-growth cereals and brassicas preferred in late winter (Wood et al. 2019b). We attempted to achieve representative coverage of age classes, species, and swan densities found within the landscape (Additional file 1: Table S2). As all three swan species regularly intermix, all swans within the same field were considered to be sharing feeding habitat. The densities of (i) Bewick's Swans and (ii) their interspecific competitors in each field (individuals $/ \mathrm{km}^{2}$ ) were calculated as the total numbers of (i) Bewick's Swans and (ii) Mute and Whooper Swans combined, divided by the total field size. Where swans were encountered during surveys, a random subset of the individuals present were filmed using a tripod-mounted Canon SX50 HS video camera (Canon Inc., Japan) for up to $20 \mathrm{~min}$, following the focal-bird sampling methods used in previous studies of swan behaviour (e.g. Keane and O'Halloran 1992; O'Hare et al. 2007; Tatu et al. 2007; Wood et al. 2019c). All individuals filmed within a given video were assigned an alphanumeric code (hereafter termed observation identity) that was unique to that 
video, such that swans that were sharing feeding habitat at the same time shared the same observation identity. We measured the air temperature $\left( \pm 0.5{ }^{\circ} \mathrm{C}\right)$ at the start of each video recording using an immersion thermometer (Breaksafe Thermometer, Brannan, UK). In this study we only considered diurnal behaviour and energy expenditure, as Bewick's Swans and the other two species typically roost in different areas within the Ouse Washes (Ponting 2014), and so competition was considered to only be likely during daylight hours.

\section{Time-activity budgets}

We used the footage obtained to construct time-activity budgets (Paulus 1988) for each individual using the focalindividual sampling method (Altmann 1974). Analysis of swan behaviours was performed using the Behavioral Observation Research Interactive Software (BORIS) developed by Friard and Gamba (2016), an event recorder that permits frame-by-frame viewing. For each video, all individuals within the video frame were watched separately, with the duration of each behaviour type noted for the duration that the focal individual remained visible. Eight behaviour categories, used in previous studies to synthesise the main activities of non-breeding swans (Nolet et al. 2002; Rees 2006; Włodarczyk 2017), were used to describe the swans' behaviour: resting, foraging, vigilance, preening (including other maintenance behaviours such as stretching), walking, flying, aggressive interactions, and non-aggressive social interactions. An aggressive interaction was defined as any interaction between the focal individual and one or more other individuals which involved giving or receiving physical or vocal threat displays or attacks (Wood et al. 2020). We also noted whether each aggressive interaction was intraspecific or interspecific (including which species the interspecific interactions were with).

\section{Energetics}

We calculated the rate of net energy gain of each observed individual by estimating their expenditure and gain of energy during their observation period. To estimate energy expenditure, we combined time-budgets with activity-specific multipliers of the basal metabolic rate (BMR) for that species and age class (Krivtsov and Mineyev 1991; Clausen et al. 2013). The basal metabolic rate for each age class in each species was calculated from the allometric equation presented by Hughes and Green (2005):

$$
\mathrm{BMR}=z \times M^{0.73}
$$

where $z$ represents the BMR value at $1 \mathrm{~kg}$ body mass (reported as 4.64 Watts for Anseriformes by Zar 1968) and $M$ was the mean body mass of the swan in kilograms (averaged for males and females; Kear 2005) (Additional file 1: Table S3).

The baseline activity-specific energetic costs (Watts) for adult Bewick's Swans were those measured experimentally by Nolet et al. (2002). We used these values to determine the multipliers of basal metabolic rate (xBMR) for each behaviour for an adult Bewick's Swan, which could then be used to estimate the energetic costs of each behaviour for all of the other swan species and age classes, assuming that the costs were proportionally equivalent (Additional file 1: Table S4). Energy expenditure for each focal individual during an observation period could thus be calculated by summing the energy expenditure spent on each behavioural activity.

To estimate the gross energy gain of swans feeding on cereal and root crops, we used the equations derived by Wood et al. (2019b), as these accurately predicted resource selection by overwintering swans within our study area. The gross energy gain $\left(E_{\mathrm{Gain}}\right.$; Joules per observation) of each observed individual was estimated as:

$$
E_{\mathrm{Gain}}=\left(I_{\mathrm{D}} \times(Q \times A)\right) \times F_{\text {Time }}
$$

where $I_{\mathrm{D}}$ was the species and age-class-specific instantaneous intake rate on a given density of either cereal or root crops (g Dry Matter/s; Wood et al. 2019b), $Q$ was the mean energy density (J/DM g; Wood et al. 2019b) of the crop type, $A$ was the proportional assimilation efficiency for a given crop type, whilst $F_{\text {Time }}$ was the total time (in seconds) that the focal swan was observed to spend on foraging. For the parameters $I_{\mathrm{D}}$ and $Q$, mean monthly values for cereal and root biomass and energy densities were available from Wood et al. (2019b). For the parameter $A$, temporally-invariant proportional assimilation efficiency values of 0.63 and 0.84 were used for cereal and root crops, respectively (Nolet et al. 2002; Amano et al. 2004).

We also accounted for additional energetic costs of thermoregulation during cold or warm weather (Bech 1980; Jenssen et al. 1989). Bech (1980) found that Mute Swans had lower and upper critical temperatures of $0.8^{\circ} \mathrm{C}$ and $15.0^{\circ} \mathrm{C}$, respectively, and hence we added an additional thermoregulatory cost to each observation made where the air temperature was outside of the range $0.8-15.0^{\circ} \mathrm{C}$. We applied this additional energetic cost by first estimating ${ }_{p} B M R$, which represented the $B M R$ of the individual outside of its thermal neutral zone $\left(\mathrm{BMR}_{\mathrm{c}}\right)$ as a proportion of its BMR within its thermal neutral zone:

$$
\begin{aligned}
& { }_{\mathrm{p}} \mathrm{BMR}=\mathrm{BMR}_{\mathrm{c}} / \mathrm{BMR}_{\mathrm{a}} \\
& \mathrm{BMR}_{\mathrm{a}}=\left(V_{\mathrm{a}} \times m\right) \times e
\end{aligned}
$$




$$
\mathrm{BMR}_{\mathrm{c}}=\left(V_{\mathrm{c}} \times m\right) \times e
$$

where $V_{\mathrm{a}}$ was the instantaneous $\mathrm{VO}_{2}$ per unit mass reported for Mute Swans within the thermal neutral zone $(0.654 \mathrm{~mL} \mathrm{O} /(\mathrm{g} \cdot \mathrm{s})), m$ was the mean body mass of the swan in grams (averaged for males and females; Kear 2005) (Additional file 1: Table S3), and $e$ was the energy yielded per $\mathrm{ml}$ of oxygen consumed $\left(20 \mathrm{~J} / \mathrm{mL} \mathrm{O}_{2}\right.$; Nolet et al. 2002). Similarly, $V_{\mathrm{c}}$ was the instantaneous $\mathrm{VO}_{2}$ per unit mass reported for Mute Swans outside of its thermal neutral zone, which was reported by Bech (1980) for both the lower and upper critical temperatures of $0.8{ }^{\circ} \mathrm{C}$ and $15.0^{\circ} \mathrm{C}$, respectively, as:

$$
\begin{aligned}
& V_{\mathrm{c}, \mathrm{t}<0.8}=(0.665-(0.014 \times t)) / 3600 \\
& V_{\mathrm{c}, \mathrm{t}>15.0}=(0.472+(0.012 \times t)) / 3600
\end{aligned}
$$

where $t$ was the air temperature $\left({ }^{\circ} \mathrm{C}\right)$. The air temperatures measured during each observation could therefore be used to adjust the baseline energetic costs of each behavioural activity.

We estimated the rate of net energy gain of each focal swan during an observation as the proportion of time the swan spent foraging multiplied by the expected instantaneous energy gain, minus energy expenditure. To facilitate comparisons across species and age classes, we converted our estimates of net energy gain from Watts to a multiple of BMR (hereafter: $x B M R$ ) for each individual. The estimates for Bewick's Swans were used in our statistical models (as described below), with the values derived for Mute and Whooper Swans reported for comparative purposes.

\section{Statistical analyses}

All statistical analyses were carried out using $\mathrm{R}$ version 3.6.3 (R Core Team 2020). To address our first objective regarding aggressive interactions among swans, we used two-sample binomial tests for equality of proportions (Crawley 2013) to assess the significance of the differences in the proportion of intraspecific and interspecific aggressive interactions recorded. Separate tests were conducted for each species and age class, with significant differences attributed where $P<0.05$.

To address our second objective regarding impacts of competition on the behaviour and energetics of individual Bewick's Swans, we ran separate sets of models for each of our four response variables: (i) the probability of aggression observed during an observation; (ii) the proportion of time spent on foraging during an observation; (iii) the proportion of time spent on vigilance during an observation; and (iv) the rate of net energy gain during an observation. We ran linear mixed effects models, using the glmmTMB R package (Brooks et al. 2017). For each of our response variables, our set of candidate models consisted of all additive and two-way interactive combinations (that did not contain correlated variables, see below) of (i) the density of Bewick's Swans sharing feeding habitat with the focal individual (individuals $/ \mathrm{km}^{2}$ ); (ii) the combined density of Mute and Whooper Swans sharing feeding habitat with the focal individual (individuals/ $\mathrm{km}^{2}$ ); and (iii) the age class of the focal individual (cygnet or adult). To account for non-independence of individuals within the same flock, we modelled observation identity as a random intercept in each model. Within each model, each observation was weighted by the duration of the observation period ( $\mathrm{min}$ ), to reflect that observation periods were not equal among focal individuals, and that longer observations potentially contained more information than shorter observation periods. For models of foraging, vigilance, and net energy gain, these linear mixed effects models (LMMs) featured Gaussian error structures. In all models of foraging and vigilance, the proportions of time spent on these behaviours were logit-transformed using the car package (Fox et al. 2018) to ensure that model assumptions were met (Warton and Hui 2011); similarly, net energy gain values (xBMR) were rescaled between 0 and 1 using the scales package (Wickham and Seidel 2020), and then logit-transformed using the same approach. In contrast, we used generalized linear mixed effects models (GLMMs), with binomial error structures, for the probability of aggression. Earlier attempts to use zero-inflated generalised linear mixed models (ZIGLMMS) for the time spent on aggressive interactions (based on the approach of Wood et al. 2020) resulted in models which failed to converge, so instead we opted to model the probability of occurrence for aggressive interactions. Model assumptions were checked using the performance package (Lüdecke et al. 2020). In addition, we calculated the variance inflation factor (VIF) associated with each explanatory variable, using the performance package (Lüdecke et al. 2020). We found that interactions between focal age class and Bewick's Swan density had VIF values of $<5.0$ (Dormann et al. 2013), and so models containing this interaction were removed from our sets of candidate models for each of the four response variables, and were not considered further, so that multicollinearity did not influence the efficiency and reliability of parameter estimation for our models (Dormann et al. 2013).

For each of our response variables, we assessed the performance of each non-collinear candidate model using second-order Akaike's Information Criterion (AICc) values (Burnham et al. 2011), with any model with a $\triangle$ AICc value of $\leq 6.0$ considered to have received support in the data (Richards et al. 2011). To be considered competitive, 
a model also had to perform better (AICc $\geq 6.0$ ) than the null model, i.e. a model comprised of an intercept and no other parameters. In addition to the AICc threshold, we also took an additional step to minimize the effects of uninformative parameters (sensu; Arnold 2010) during model comparisons; models were judged competitive only if the AICc value associated with a more complex form of the model (i.e. one containing additional parameters) was lower than the simpler model (Harrison et al. 2018). We assessed the proportion of the variance in each response variable explained by a candidate model based on the two values of adjusted $R^{2}$ proposed for mixed effects models by Nakagawa et al. (2017), calculated using the performance package (Lüdecke et al. 2020). The marginal $R^{2}$ indicated the proportion of variance explained by the fixed effects alone, whilst the conditional $R^{2}$ indicated the proportion of variance explained by both the fixed and random effects.

\section{Results}

\section{Aggression}

Across all species and age classes, the mean $( \pm 95 \%$ CI) proportion of time spent by focal swans engaged in aggressive interactions was $0.011 \pm 0.002$ (Table 1). Intraspecific interactions accounted for $0.010 \pm 0.002$ of the total time budgets, whilst interspecific interactions represented $0.010 \pm 0.001$ of the total time for which swans were observed (Additional file 1: Table S5). Thus, across all species and age classes, intraspecific and interspecific aggression accounted for 0.872 and 0.128 of the total time spent on aggressive behaviours, respectively. The proportion of aggressive interactions that involved conspecifics was significantly greater than the proportion involving heterospecifics for all swans except Mute Swan cygnets (Table 2).

Model selection revealed that the probability of a Bewick's Swan engaging in an aggressive interaction was best-explained by a model comprised of additive and twoway interactive effects of the age class of the focal individual and the combined density of Mute and Whooper Swans sharing the feeding habitat with the focal individual (Table 3). This best-supported model accounted for $65.5 \%$ of the total Akaike weights, whilst the fixed effects alone and the fixed and random effects together were responsible for $1.2 \%$ and $83.7 \%$ of the betweenindividual variation in Bewick's Swan aggression probability (Table 3). A second model, identical to the first except for an additional additive effect of Bewick's Swan density, had an associated $\triangle \mathrm{AICc}$ value of 1.28 ; however, the higher AICc value of the model containing the

Table 1 A summary of the mean $( \pm 95 \% \mathrm{Cl})$ percentage of time spent on each activity, from the diurnal time-activity budgets recorded for our focal swans, together with their estimates rates of net energy gain (see main text)

\begin{tabular}{lllllll}
\hline Category & Bewick's adult & Bewick's cygnet & Mute adult & Mute cygnet & Whooper adult & Whooper cygnet \\
\hline No. individuals observed $(n)$ & 300 & 85 & 106 & 23 & 444 & 125 \\
Aggression (\%) & $1.7( \pm 0.5)$ & $0.7( \pm 0.3)$ & $1.7( \pm 1.0)$ & $1.4( \pm 1.7)$ & $0.9( \pm 0.3)$ & $0.5( \pm 0.3)$ \\
Foraging (\%) & $41.4( \pm 3.0)$ & $42.0( \pm 4.9)$ & $45.6( \pm 4.6)$ & $57.3( \pm 9.8)$ & $43.3( \pm 2.6)$ & $45.5( \pm 4.2)$ \\
Flying (\%) & $0.2( \pm 0.2)$ & $0.3( \pm 0.3)$ & $0.0( \pm 0.0)$ & $0.1( \pm 0.1)$ & $0.3( \pm 0.1)$ & $0.3( \pm 0.2)$ \\
Preening (\%) & $4.4( \pm 1.0)$ & $7.9( \pm 1.9)$ & $15.0( \pm 3.9)$ & $12.3( \pm 8.0)$ & $8.5( \pm 1.3)$ & $11.7( \pm 2.6)$ \\
Resting (\%) & $9.1( \pm 2.5)$ & $8.3( \pm 3.6)$ & $6.9( \pm 3.4)$ & $3.8( \pm 6.8)$ & $17.6( \pm 2.8)$ & $11.4( \pm 3.4)$ \\
Social (\%) & $0.4( \pm 0.1)$ & $1.0( \pm 0.9)$ & $0.2( \pm 0.2)$ & $0.1( \pm 0.1)$ & $0.6( \pm 0.3)$ & $0.4( \pm 0.1)$ \\
Vigilance (\%) & $25.0( \pm 2.2)$ & $23.3( \pm 3.3)$ & $25.3( \pm 3.2)$ & $18.4( \pm 4.6)$ & $17.7( \pm 1.6)$ & $18.0( \pm 2.7)$ \\
Walking (\%) & $17.8( \pm 2.1)$ & $16.5( \pm 4.1)$ & $5.2( \pm 1.3)$ & $6.7( \pm 2.9)$ & $11.2( \pm 1.3)$ & $12.3( \pm 3.1)$ \\
Net energy gain (xBMR) & $2.0( \pm 0.5)$ & $1.4( \pm 0.6)$ & $5.0( \pm 0.7)$ & $4.5( \pm 1.0)$ & $4.2( \pm 0.6)$ & $3.6( \pm 0.9)$ \\
\hline
\end{tabular}

Table 2 A comparison of the proportions of intraspecific $\left(P_{\text {Intra }}\right)$ and interspecific $\left(P_{\text {Inter }}\right)$ aggressive interactions for each swan species and age class

\begin{tabular}{llllllrr}
\hline Species & Age class & $\boldsymbol{P}_{\text {Intra }}$ & $\boldsymbol{P}_{\text {Intra }} \mathbf{9 5 \%} \mathbf{C l}$ & $\boldsymbol{P}_{\text {Inter }}$ & $\boldsymbol{P}_{\text {Inter }} \mathbf{9 5 \%} \mathrm{Cl}$ & $\boldsymbol{X}^{\mathbf{2}}$ & $\boldsymbol{P}_{\text {value }}$ \\
\hline \multirow{2}{*}{ Bewick's } & Adult & 0.744 & $0.724-0.820$ & 0.226 & $0.180-0.276$ & 184.3 & $<0.001$ \\
& Cygnet & 0.882 & $0.761-0.956$ & 0.118 & $0.044-0.239$ & 56.6 & $<0.001$ \\
\multirow{2}{*}{ Mute } & Adult & 0.842 & $0.740-0.916$ & 0.158 & $0.084-0.260$ & 68.4 & $<0.001$ \\
& Cygnet & 0.714 & $0.419-0.916$ & 0.286 & $0.084-0.581$ & 3.6 & 0.059 \\
\multirow{2}{*}{ Whooper } & Adult & 0.852 & $0.808-0.890$ & 0.148 & $0.110-0.192$ & 305.6 & $<0.001$ \\
& Cygnet & 0.918 & $0.804-0.977$ & 0.082 & $0.023-0.196$ & 65.3 & $<0.001$ \\
\hline
\end{tabular}


Table 3 A summary of our best-supported models $(\triangle \mathrm{AIC}<6.0)$ and null models of Bewick's Swan behavioural activities and net energy gain (NEG)

\begin{tabular}{|c|c|c|c|c|c|c|c|c|c|}
\hline Variable & Model & $k$ & AICc & $\triangle \mathrm{AICC}$ & $R L$ & wi & $E R$ & $R_{\mathrm{m}}^{2}$ & $R_{c}^{2}$ \\
\hline \multirow{3}{*}{ Aggression } & $1+A+C+(A: C)+(1 \mid U)$ & 5 & 2707.16 & 0.00 & 1.00 & 0.655 & 1.00 & 0.012 & 0.837 \\
\hline & $1+A+B+C+(A: C)+(1 \mid U)$ & 6 & 2708.44 & 1.28 & 0.53 & 0.345 & 1.90 & 0.035 & 0.845 \\
\hline & $1+(1 \mid U)$ & 2 & 2726.01 & 18.85 & 0.00 & 0.000 & $12,406.39$ & 0.000 & 0.824 \\
\hline \multirow[t]{7}{*}{ Foraging } & $1+A+B+C+(A: C)+(1 \mid U)$ & 7 & 8101.00 & 0.00 & 1.00 & 0.354 & 1.00 & 0.131 & 0.590 \\
\hline & $1+A+B+C$ & 6 & 8101.85 & 0.84 & 0.66 & 0.232 & 1.52 & 0.130 & 0.590 \\
\hline & $1+A+B+C+(A: C)+(B: C)+(1 \mid U)$ & 8 & 8103.04 & 2.04 & 0.36 & 0.128 & 2.77 & 0.128 & 0.588 \\
\hline & $1+A+C+(A: C)+(1 \mid U)$ & 6 & 8103.26 & 2.25 & 0.32 & 0.115 & 3.08 & 0.044 & 0.578 \\
\hline & $1+A+B+C+(B: C)+(1 \mid U)$ & 7 & 8103.89 & 2.88 & 0.24 & 0.084 & 4.23 & 0.127 & 0.589 \\
\hline & $1+A+C+(1 \mid U)$ & 5 & 8104.20 & 3.20 & 0.20 & 0.071 & 4.95 & 0.043 & 0.579 \\
\hline & $1+(1 \mid U)$ & 3 & 8177.10 & 76.10 & 0.00 & 0.000 & $3.34 \times 10^{16}$ & 0.000 & 0.593 \\
\hline \multirow[t]{9}{*}{ Vigilance } & $1+A+B+C+(B: C)+(1 \mid U)$ & 7 & 6845.36 & 0.00 & 1.00 & 0.370 & 1.00 & 0.073 & 0.595 \\
\hline & $1+A+B+C+(A: C)+(B: C)+(1 \mid U)$ & 8 & 6845.79 & 0.43 & 0.81 & 0.298 & 1.24 & 0.073 & 0.597 \\
\hline & $1+\mathrm{A}+\mathrm{C}+(1 \mid \mathrm{U})$ & 5 & 6848.52 & 3.16 & 0.21 & 0.076 & 4.84 & 0.025 & 0.622 \\
\hline & $1+A+B+C+(1 \mid U)$ & 6 & 6848.71 & 3.35 & 0.19 & 0.069 & 5.33 & 0.067 & 0.627 \\
\hline & $1+A+C+(A: C)+(1 \mid U)$ & 6 & 6848.88 & 3.52 & 0.17 & 0.064 & 5.81 & 0.025 & 0.623 \\
\hline & $1+A+B+C+(A: C)+(1 \mid U)$ & 7 & 6849.15 & 3.79 & 0.15 & 0.056 & 6.65 & 0.067 & 0.629 \\
\hline & $1+A$ & 4 & 6849.69 & 4.33 & 0.12 & 0.043 & 8.69 & 0.007 & 0.635 \\
\hline & $1+A+B+(1 \mid U)$ & 5 & 6850.88 & 5.51 & 0.06 & 0.024 & 15.75 & 0.031 & 0.638 \\
\hline & $1+(1 \mid U)$ & 3 & 6901.17 & 55.81 & 0.00 & 0.000 & $1.32 \times 10^{12}$ & 0.000 & 0.623 \\
\hline \multirow[t]{13}{*}{ NEG } & $1+A+C+(1 \mid U)$ & 5 & 4292.69 & 0.00 & 1.00 & 0.165 & 1.00 & 0.013 & 0.538 \\
\hline & $1+A+(1 \mid U)$ & 4 & 4292.94 & 0.24 & 0.89 & 0.147 & 1.13 & 0.000 & 0.547 \\
\hline & $1+C+(1 \mid U)$ & 4 & 4293.06 & 0.37 & 0.83 & 0.137 & 1.20 & 0.012 & 0.536 \\
\hline & $1+(1 \mid U)$ & 3 & 4293.41 & 0.72 & 0.70 & 0.115 & 1.43 & 0.000 & 0.546 \\
\hline & $1+A+B+C+(1 \mid U)$ & 6 & 4293.93 & 1.24 & 0.54 & 0.089 & 1.86 & 0.030 & 0.540 \\
\hline & $1+B+C+(1 \mid U)$ & 5 & 4294.29 & 1.59 & 0.45 & 0.075 & 2.22 & 0.030 & 0.538 \\
\hline & $1+A+B+(1 \mid U)$ & 5 & 4294.67 & 1.97 & 0.37 & 0.062 & 2.68 & 0.009 & 0.549 \\
\hline & $1+A+C+(A: C)+(1 \mid U)$ & 6 & 4294.75 & 2.06 & 0.36 & 0.059 & 2.80 & 0.013 & 0.538 \\
\hline & $1+B+(1 \mid U)$ & 4 & 4295.14 & 2.45 & 0.29 & 0.049 & 3.40 & 0.008 & 0.547 \\
\hline & $1+A+B+C+(B: C)+(1 \mid U)$ & 7 & 4295.98 & 3.28 & 0.19 & 0.032 & 5.17 & 0.032 & 0.541 \\
\hline & $1+A+B+C+(A: C)+(1 \mid U)$ & 7 & 4296.00 & 3.30 & 0.19 & 0.032 & 5.22 & 0.030 & 0.540 \\
\hline & $1+B+C+(B: C)+(1 \mid U)$ & 6 & 4296.32 & 3.62 & 0.16 & 0.027 & 6.12 & 0.031 & 0.539 \\
\hline & $1+A+B+C+(A: C)+(B: C)+(1 \mid U)$ & 8 & 4298.06 & 5.36 & 0.07 & 0.011 & 14.61 & 0.032 & 0.541 \\
\hline
\end{tabular}

For each behaviour the best-supported model is indicated in bold. $k$ represents the number of parameters in the model. $R^{2}{ }_{\mathrm{m}}$ and $R^{2}{ }_{\mathrm{c}}$ indicate the proportions of variance explained by the fixed effects alone and both the fixed and random effects, respectively. $R L$, wi, and $E R$ represent the relative likelihood, Akaike weight, and evidence ratio, respectively. Model parameters: intercept (1), density of Bewick's Swans sharing feeding habitat with the focal individual ( $B$ ), density of Mute and Whooper Swans sharing feeding habitat with the focal individual $(C)$, age class of the focal individual $(A)$, and observation identity $(U)$. The symbols + and: represented additive and interactive effects, respectively, within models

additional variable suggested that the Bewick's Swan density variable was uninformative, and so this model was not considered further. No other candidate model had an $\triangle$ AICc value of $\leq 6.0$ of the best-supported model. The best-supported model also performed substantially better than the null model (Table 3). The best-supported model featured a negative interaction between Mute and Whooper Swan density and Bewick's Swan age class, such that the probability that a Bewick's Swan cygnet was engaged in aggression during the observation increased with Mute and Whooper Swan density, whereas no such relationship was found for adult Bewick's Swans (Table 4; Fig. 2).

\section{Foraging}

Based on our focal observations, the mean $( \pm 95 \% \mathrm{CI})$ proportion of observed time spent on foraging by Bewick's Swans was $0.414( \pm 0.003)$ for adults and $0.420( \pm 0.049)$ for cygnets (Table 1). Whilst the foraging effort observed for adult Bewick's Swans was the lowest observed for any species and age class, the greatest foraging effort was $0.573( \pm 0.098)$ by cygnet Mute Swans (Table 1$)$. These 
Table 4 Parameter estimates for the models of Bewick's Swan behaviour and energetics with the lowest AICc values

\begin{tabular}{|c|c|c|c|c|c|c|c|}
\hline Variable & Effect type & Parameter & VIF & Mean & SE & Variance & SD \\
\hline \multirow[t]{5}{*}{ Aggression } & Fixed & Intercept & - & -2.09 & 0.83 & - & - \\
\hline & & A & 1.94 & -0.25 & 0.18 & - & - \\
\hline & & $C$ & 1.00 & $5.5 \times 10^{-4}$ & $7.4 \times 10^{-4}$ & - & - \\
\hline & & $A: C$ & 1.94 & $1.4 \times 10^{-2}$ & $3.3 \times 10^{-3}$ & - & - \\
\hline & Random & Observation ID & - & - & - & 16.7 & 4.1 \\
\hline \multirow[t]{7}{*}{ Foraging } & Fixed & Intercept & - & -0.91 & 0.19 & - & - \\
\hline & & $A$ & 2.00 & 0.40 & 0.05 & - & - \\
\hline & & B & 1.21 & $8.00 \times 10^{-4}$ & $4.00 \times 10^{-4}$ & - & - \\
\hline & & C & 1.21 & $5.00 \times 10^{-4}$ & $1.00 \times 10^{-4}$ & - & - \\
\hline & & $A: C$ & 1.99 & $-1.40 \times 10^{-3}$ & $8.00 \times 10^{-4}$ & - & - \\
\hline & Random & Observation ID & - & - & - & 0.79 & 0.89 \\
\hline & & Residual & - & - & - & 0.71 & 0.84 \\
\hline \multirow[t]{7}{*}{ Vigilance } & Fixed & Intercept & - & -0.94 & 0.17 & - & - \\
\hline & & A & 1.00 & -0.23 & 0.03 & - & - \\
\hline & & B & 1.06 & $-3.00 \times 10^{-4}$ & $3.00 \times 10^{-4}$ & - & - \\
\hline & & C & 1.10 & $6.00 \times 10^{-4}$ & $4.00 \times 10^{-4}$ & - & - \\
\hline & & $B: C$ & 1.05 & $-3.59 \times 10^{-6}$ & $-3.96 \times 10^{-6}$ & - & - \\
\hline & Random & Observation ID & - & - & - & 0.61 & 0.78 \\
\hline & & Residual & - & - & - & 0.48 & 0.69 \\
\hline \multirow{3}{*}{ Net energy gain } & Fixed & Intercept & - & 0.79 & 0.08 & - & - \\
\hline & Random & Observation ID & - & - & - & 0.26 & 0.51 \\
\hline & & Residual & - & - & - & 0.21 & 0.46 \\
\hline
\end{tabular}

The variance and SD associated with the random effects, as well as the Variance Inflation Factor (VIF) associated with each parameter, are also indicated. Foraging and vigilance variables were logit-transformed response variable, whilst net energy gain was rescaled logit-transformed response variable. Model parameters: intercept (1), density of Bewick's Swan sharing feeding habitat with focal individual (B), density of Mute and Whooper Swans sharing feeding habitat with focal individual ( $C$ ), age class of focal individual $(A)$, and observation identity $(U)$. Adult parameter values refer to cygnets relative to adults

diurnal foraging effort values meant that, over the course of a 24-h period, adult and cygnet Bewick's Swans spent $0.153( \pm 0.106)$ and $0.148( \pm 0.090)$, respectively, of each day foraging (Additional file 1: Table S6).

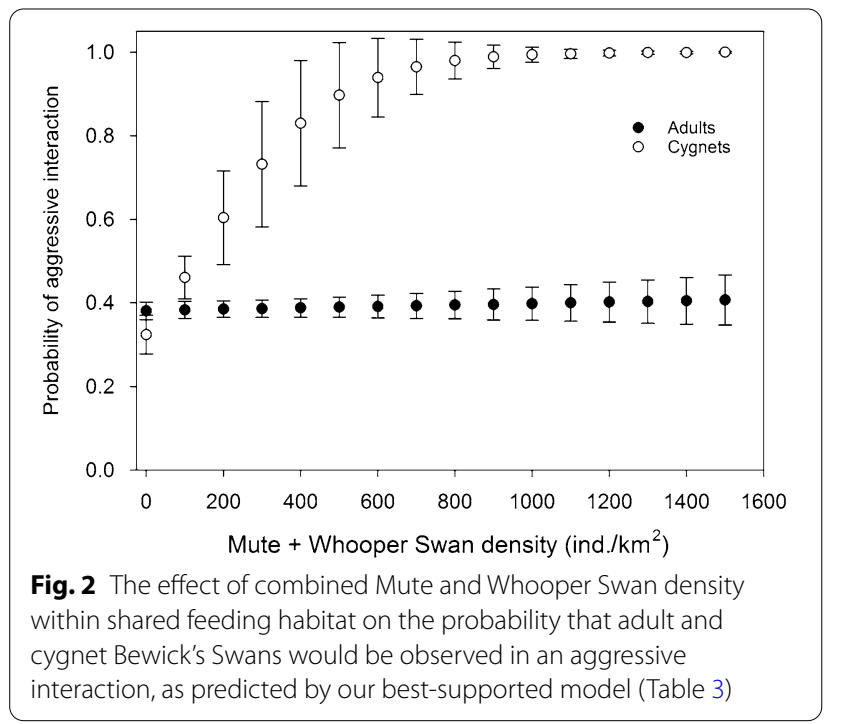

A comparison of our candidate models indicated that the proportion of time spent by Bewick's Swans on foraging behaviour was best explained by a model comprised of the age class of the focal individual, the density of other Bewick's Swans sharing the feeding habitat, and the combined density of Mute and Whooper Swans sharing the feeding habitat with the focal individual. This bestsupported model accounted for $35.4 \%$ of the total Akaike weights, whilst the fixed effects alone and the fixed and random effects together were responsible for $13.1 \%$ and $59.0 \%$ of the between-individual variation in Bewick's Swan foraging effort (Table 3). A further five candidate models had associated AICc values within 6.0 of the best-supported models; however, each of these models accounted for a lower percentage of the total Akaike weights, had lower marginal and conditional $R^{2}$ values, and higher evidence ratios, than the best-supported model. Crucially, the variable describing the density of Mute and Whooper Swans was contained in all six of the top models, and in each case a positive effect size was detected. The best-supported model moreover performed substantially better than the null model (Table 3). 


\section{a Adults}

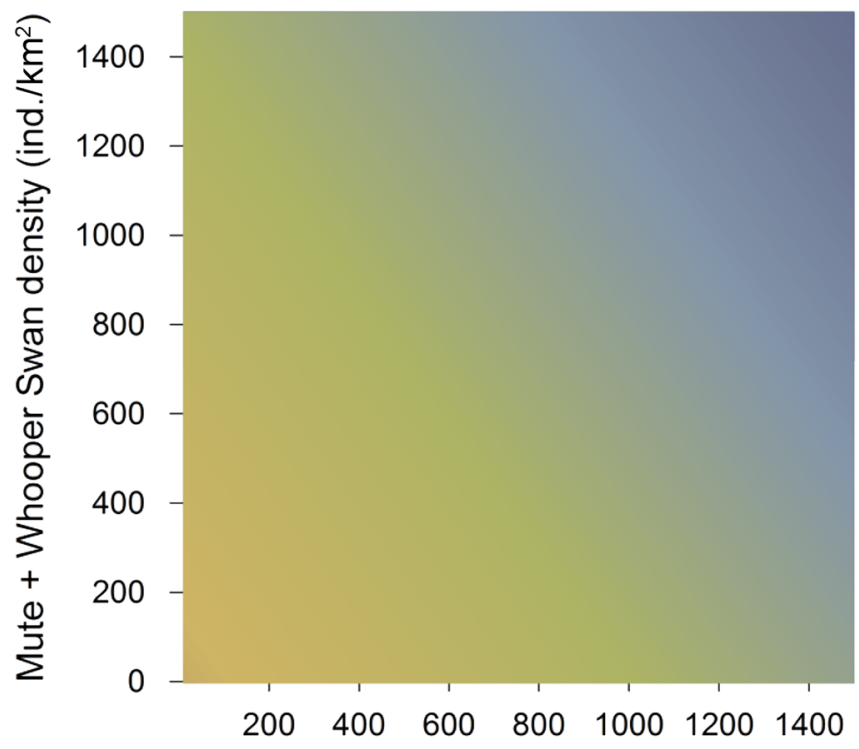

Prop. time foraging

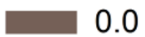

0.1
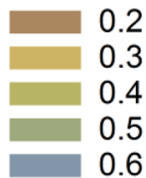

0.7

Bewick's Swan density (ind./ $\mathrm{km}^{2}$ )

\section{b Cygnets}

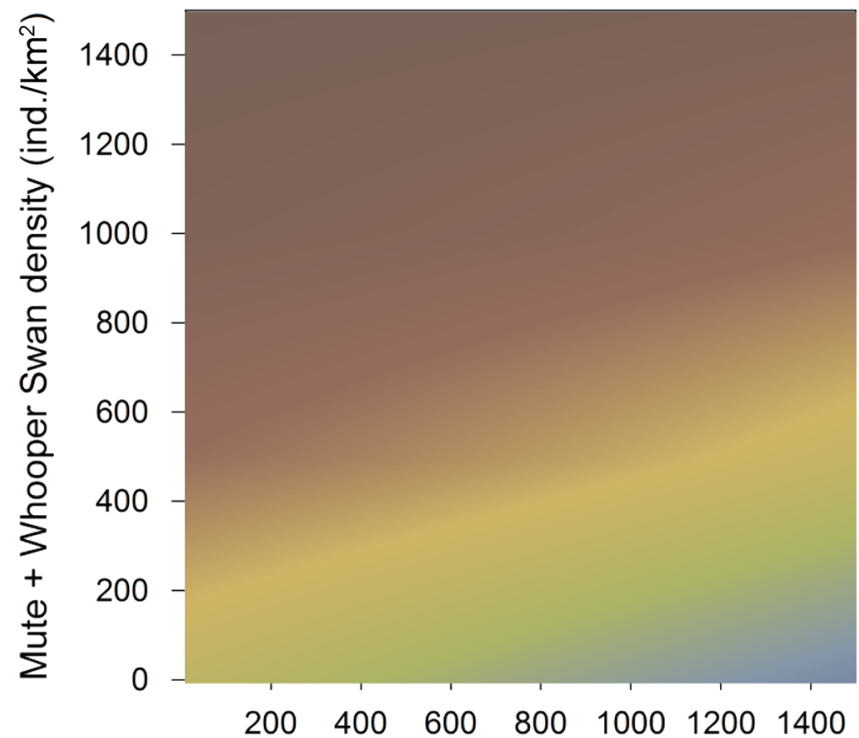

Prop. time foraging

Bewick's Swan density (ind. $/ \mathrm{km}^{2}$ )

Fig. 3 The effects of Bewick's Swan density and combined Mute and Whooper Swan density on the proportion of time spent foraging by a adult and $\mathbf{b}$ cygnet Bewick's Swans, as predicted by our best-supported model (Table 3)

The best-supported model for foraging indicated that the proportion of time spent by Bewick's Swans on foraging was positively related to the density of Bewick's Swans sharing the feeding habitat (Table 4; Fig. 3). However, a negative interaction between Mute and Whooper
Swan density and age class was detected, such that the proportion of time spent by cygnets on foraging declined with Mute and Whooper Swan density, in contrast to the positive relationship found for adult Bewick's Swans (Table 4; Fig. 3). 


\section{Vigilance}

Based on our observations of focal swans, the mean $( \pm 95 \% \mathrm{CI})$ proportion of time spent engaged in vigilance behaviour ranged from $0.177( \pm 0.016)$ for adult Whooper Swans to $0.253( \pm 0.032)$ for adult Mute Swans (Table 1). In comparison, adult and cygnet Bewick's Swans respectively spent $0.250( \pm 0.022)$ and 0.233 $( \pm 0.033)$ of their time on vigilance behaviour (Table 1$)$.

Our model selection process identified eight noncollinear models that were potentially competitive, with $\triangle \mathrm{AICc}$ values of $<6.0$ (Table 3 ). The model with the lowest AICc value was comprised of additive effects of age class, Bewick's Swan density, and the combined density of Mute and Whooper Swans, as well as an interaction between Bewick's Swan densities and combined Mute and Whooper Swan density; this model accounted for $37.0 \%$ of the total Akaike weights, whilst the fixed effects alone and the fixed and random effects together were responsible for $7.3 \%$ and $59.5 \%$ of the between-individual variation in Bewick's Swan vigilance (Table 3). The model with the next-lowest AICc value was identical to the first, except that it contained one additional parameter, an interaction between age class and Bewick's Swan density; however, despite the addition of this parameter the AICc value increased and so we considered the parameter to be uninformative and the model was not considered further (Table 3). The remaining six potentially competitive models each received substantially lower support in the data, with each model accounting for $\leq 7.6 \%$ of the total Akaike weights and their fixed effects accounting for $\leq 6.7 \%$ of the between-individual variation in vigilance. We therefore considered the lowest-AICc model to be our best-supported model of Bewick's Swan vigilance behaviour.

The best-supported model indicated that the proportion of time spent by Bewick's Swans on vigilance differed between adults and cygnets, with adults devoting more time to vigilance compared with cygnets (Table 4; Fig. 4). Individuals within low density Bewick's Swan flocks (<c. 200 individuals $/ \mathrm{km}^{2}$ ) spent more time on vigilance irrespective of age when amongst higher densities of Mute and Whooper Swans, whilst individuals within high density Bewick's Swan flocks showed the opposite pattern, as indicated by a negative interaction between these variables (Table 4; Fig. 4).

\section{Net energy gain}

The mean $( \pm 95 \% \mathrm{CI})$ estimated rates of net energy gain values for Bewick's Swans were $2.0( \pm 0.5)$ xBMR for adults and 1.4 $( \pm 0.6)$ xBMR for cygnets (Table 1$)$. The value for Bewick's Swan cygnets was the lowest estimated for any swan species and age class, whilst the maximum was $5.0( \pm 0.7)$ xBMR for adult Mute Swans (Table 1).
Selection of the candidate models of Bewick's Swan net energy gain indicated that 13 non-collinear models had associated $\triangle \mathrm{AICc}$ values of $<6.0$ (Table 3 ). The implication of this is that no combination of explanatory variables received substantially more support in the data than the null model $(\triangle \mathrm{AICC}=0.72)$, and hence the evidence for any effects of these explanatory variables must be considered to be weak. In accordance with this interpretation, none of the candidate models achieved a marginal $R^{2}$ value of $>3.2 \%$, suggesting that the explanatory variables could explain little of the between-individual variation in net energy gain (Table 3 ).

\section{Discussion}

In our study, we present the first detailed assessment of the potential effects of competition between the Bewick's Swan, and two larger competitors, the Mute Swan and Whooper Swan. Our investigation of individual behaviour and energetics indicated that, whilst Bewick's Swans exhibited some differences in behaviour in the presence of Mute and Whooper Swans, there were no detectable effects on estimated rates of net energy gain at our study site.

The overall level of aggression observed in our study population was low, with a mean $( \pm S D)$ proportion of time spent on aggression by our three focal species of only $0.011 \pm 0.035$. In comparison, proportions of $0.033 \pm 0.047$ and $0.020 \pm 0.036$ were reported for swans and all waterbirds, respectively, in a recent meta-analysis of behavioural studies (Wood et al. 2017). Indeed, some previous studies of wintering waterbirds have reported up to 0.35 of time spent on aggressive interactions (e.g. Black et al. 1992). The low levels of aggression amongst our study population may reflect the open landscape and abundant food resources in the area surrounding the Ouse Washes, which allows the birds to space themselves out and thereby limit interference competition. Compared with natural plant communities, the coverage, biomass, and energetic density of agricultural crops is much more homogeneous (Robinson and Sutherland 2002). Hence, there is likely to be limited variation in feeding patch quality within a field, which will likely minimise both interference and depletion competition. In such a habitat there is little advantage to an individual in attempting to monopolise feeding areas, which reduces the likelihood of aggression over food resources.

Where aggressive interactions were observed, our data showed that these were typically directed towards individuals of the same species. Most aggression from Mute and Whooper Swans is therefore towards their conspecifics, rather than towards Bewick's Swans. Only for Mute Swan cygnets could a statistically significant bias towards conspecific aggression not be demonstrated, which likely 

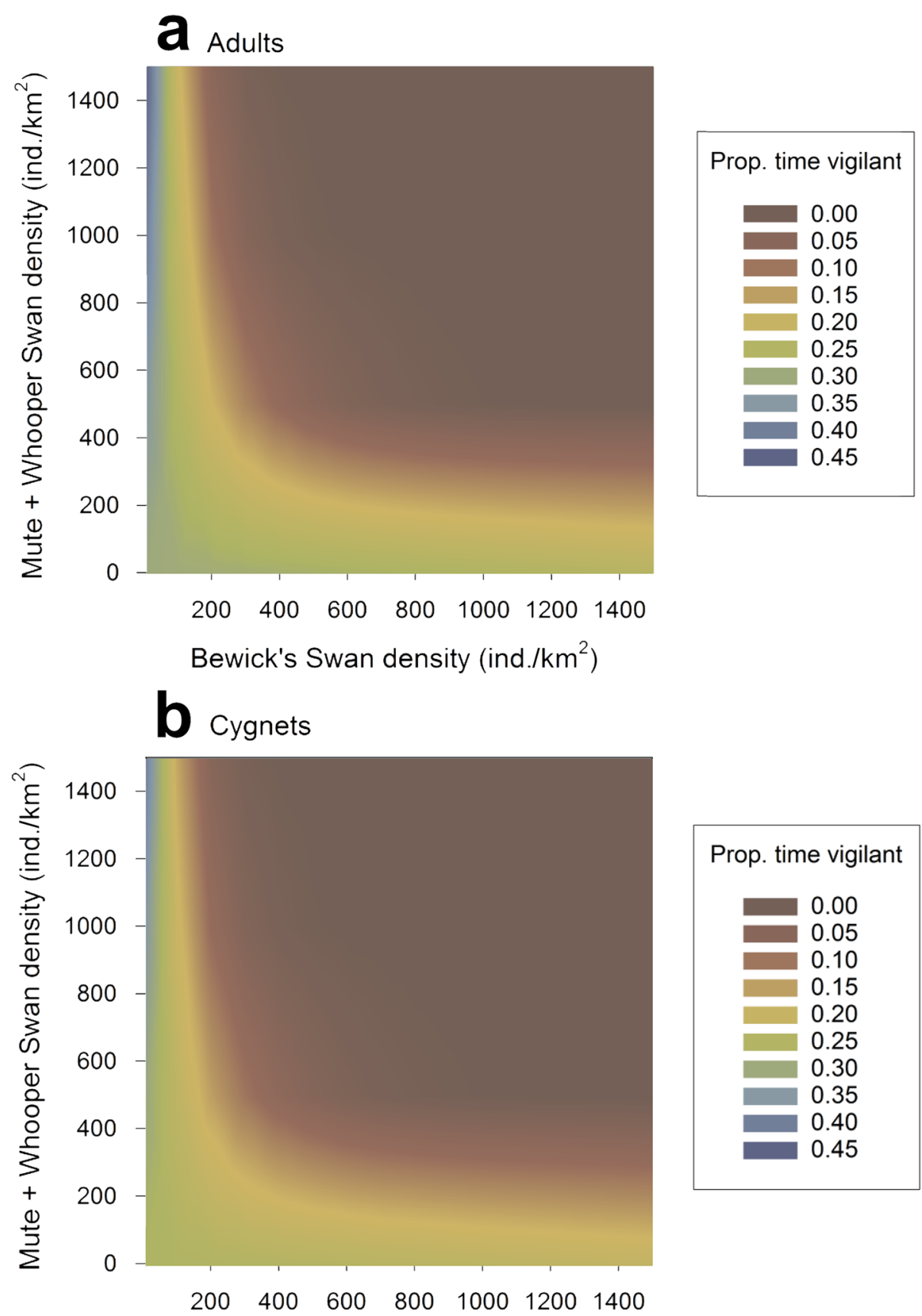

Prop. time vigilant

Bewick's Swan density (ind. $/ \mathrm{km}^{2}$ )

Fig. 4 The effects of Bewick's Swan density and combined Mute and Whooper Swan density on the proportion of time spent on vigilance behaviour by a adult and $\mathbf{b}$ cygnet Bewick's Swans, as predicted by our best-supported model (Table 3)

reflects the small sample size obtained for this group. Our findings concur with earlier research on these three species in aquatic habitats, which found that proportionally between 0.59 and 0.80 of all observed aggression was intraspecific (Wood et al. 2020). An earlier study of Mute Swans by Włodarczyk and Minias (2015) reported similarly that 0.80 of all aggressive behaviour involved conspecifics. Despite this predominance of intraspecific aggression, we did detect that Bewick's Swan cygnets had an increased likelihood of engaging in aggressive interactions when sharing feeding habitat with higher densities of interspecific competitors. In contrast, adult Bewick's 
Swans showed no such density-dependent response. Our results may have been because cygnets are less experienced in social interactions and so are more likely to become involved in aggressive interactions when surrounded by higher numbers of competitors. It should be noted, however, that the proportion of between-individual variance accounted for by our best-supported model was relatively low (0.012; Table 3$)$, which may reflect that the behaviours of individuals are influenced by a wide range of intrinsic and extrinsic variables (Rees et al. 2005; Wood et al. 2020).

Adult and cygnet Bewick's Swans showed opposing responses in their foraging behaviour to increasing interspecific competitor densities, with adults increasing their foraging effort whilst cygnets showed reduced foraging. The response of cygnets may be linked to our earlier finding regarding aggression, as individuals that engaged in aggressive interactions potentially had less time to spend on foraging. In contrast, the positive association between adult Bewick's Swan foraging effort and interspecific competitor densities may have been due to perceived depletion competition (Gyimesi et al. 2010), whereby individuals increased their foraging efforts to consume a greater share of a limited resource within a field. An alternative explanation for the positive association between adult Bewick's Swan foraging effort and interspecific competitor densities was that, because overwintering swans preferentially select the most profitable feeding habitats (Wood et al. 2019b), high density flocks indicated high quality feeding habitats, and so individuals would be expected to maximise foraging effort in such high quality habitats. Despite these effects, it is important to note that the mean proportions of time spent foraging by adult (0.414) and cygnet (0.420) Bewick's Swans were within the range of value reported previously for swans (e.g. Keane and O'Halloran 1992; O'Donoghue and O'Halloran 1994; O'Hare et al. 2007; Tatu et al. 2007; Nuijten et al. 2020c), which suggests that the Bewick's Swans in our study area were not suffering from limited access to food, either due to low availability or high interference competition.

There was also some evidence that sharing feeding habitat with interspecific competitors could affect the proportion of time that Bewick's Swans spent engaged in vigilance. However, the effect was complex, which may reflect the fact that for swans, both conspecific and heterospecific swans may provide vigilance against predators and humans, but also represent a potential threat due to the possibility of aggression and competition for shared food resources. When among low densities of conspecifics (<c. 200 individuals $/ \mathrm{km}^{2}$ ), individual Bewick's Swans spent more time on vigilance in the presence of higher densities of Mute and Whooper Swans, whilst individuals within higher density Bewick's Swan flocks showed the opposite pattern. This could indicate that, as winter Bewick's Swan numbers have decreased in recent decades, the remaining Bewick's Swans could have become more likely to find themselves within smaller Bewick's Swan flocks with higher vigilance costs. Individual Bewick's Swans among larger numbers of conspecifics may receive greater protection from interspecific aggression due a dilution effect (Delm 1990), i.e. whereby an individual Bewick's Swan has a lower chance of being targeted for interspecific aggression when it is within a larger group of Bewick's Swans. The contrasting conspecific and heterospecific effects on vigilance suggests that Bewick's Swans differentiate between other Bewick's Swans and their larger interspecific competitors within shared feeding habitat. Increased competition among higher densities of Bewick's Swans may also lead to increased foraging effort and hence reduced time available to spend on vigilance, given the inherent tradeoffs between different types of behaviour; if an individual spends more time on foraging, then the amount of time spent on another behaviour must be reduced to compensate (Metcalfe and Furness 1984). The extent to which foraging and vigilance behaviours are traded off against each other by individual swans is unclear, and future research could assess how swans trade-off expenditure of time on different behavioural activities.

Despite some evidence that Bewick's Swans altered their patterns of behaviour when sharing feeding habitat with interspecific competitors, their overall rates of net energy gain at the study site were not affected. Our results suggest that swans have at least some capacity to adjust the relative amounts of time devoted to key behaviours in order to maintain consistent levels of energy gain, as predicted by Wood et al. (2021). The mean estimates of net energy gain derived indicated that all species and age classes could achieve positive energy gains during winter. This finding concurs with earlier modelling work conducted for Bewick's and Whooper Swans in our study area (Wood et al. 2019b). The achievement of positive net energy gains during winter is particularly critical for migratory species such as Bewick's Swans, which must depart the winter grounds with sufficient energy reserves to reach a subsequent staging area or stopover site. For capital breeders such as swans, the energy and body reserves required to breed successfully is gained during the preceding winter (Drent et al. 2006) and at staging sites during migration (Nolet and Drent 1998). Our finding that Bewick's Swans wintering in eastern England have positive net energy gains suggests that competition with larger congeners during winter does not hinder their subsequent migration or breeding success. 


\section{Conclusions}

In this study we found no evidence that Bewick's Swan net energy gain was affected when sharing agricultural feeding habitat with larger congeners during winter. These farmland habitats are the major feeding habitats of Bewick's Swans during winter (Beekman et al. 2019). We therefore consider it unlikely that competition between Bewick's Swans and either Mute or Whooper Swans in these agricultural habitats is a major cause of the observed decline in Bewick's Swan winter numbers. Further evidence against an impact of interspecific competition on Bewick's Swan numbers can be found in the spatial pattern of changes in numbers within the countries that comprise the winter grounds. Bewick's Swans continue to decline in the westerly countries of the range, such as the UK and the Netherlands, but are increasing in more easterly countries such as Germany (Augst et al. 2019; Beekman et al. 2019; Nuijten et al. 2020b). Whooper and Mute Swans, however, have both been increasing in numbers in both the western and eastern parts of the Bewick's Swans' winter grounds (Hall et al. 2015; Laubek et al. 2019; Wood and Włodarczyk 2020). If interspecific competition on the winter grounds was a major driver of Bewick's Swan decline through effects on behaviour and energetics, we would have expected to observe declines wherever the species overlapped, rather than only in the countries in the west of the range. The spatial pattern of declines and increases in Bewick's Swan numbers across the winter range are, however, consistent with short-stopping due to climate change, which has caused milder winters across Europe in recent years (Nuijten et al. 2020b). Further to the effects of climate, future research into fluctuations in Bewick's Swan numbers should investigate the role that known sources of mortality, such as illegal shooting (Newth et al. 2019), could have played in observed decline. In addition, other factors that could have led to deleterious environmental changes in the overwintering grounds, such as the expansion of energy infrastructure that poses collision risk to swans and other large birds, should be considered in future assessments.

It is important to note, however, that our findings do not preclude impacts of competition in other parts of the species' range, such as stopover sites and breeding areas. Some stopover sites have limited aquatic food resources that have been shown to be depleted by migrating Bewick's Swans during their stopover period (Nolet and Drent 1998). Increases of interspecific competitors at such sites could further limit the food supplies available to the sub-dominant Bewick's Swans. There is also the potential for increased competition to affect Bewick's Swan use of aquatic food resources such as macrophyte tubers, as studies have shown that greater summer grazing of above-ground macrophyte tissues by waterbirds such as Mute Swans can reduce the subsequent availability of tubers for Bewick's Swans (Hidding et al. 2009).

\section{Supplementary Information}

The online version contains supplementary material available at https://doi. org/10.1186/s40657-021-00282-5.

Additional file 1: Table S1. Observation sample sizes. Table S2. A summary of explanatory variables. Table S3. Key swan values used in energetics calculations. Table S4. Swan behavioural energetic costs. Table S5.

Time spent on aggression. Table S6. Time spent on foraging.

\section{Acknowledgements}

We are grateful to Leigh Marshall and Louise Clewley for their support with fieldwork, and the landowners for granting access to the study area. Thanks to the handling editor, Professor Lei Cao, as well as two anonymous reviewers, for their positive responses and constructive comments on our study. Our article contains Wetland Bird Survey (WeBS) data from Waterbirds in the UK 2017/18, copyright and database right 2019; WeBS is a partnership jointly funded by the BTO, RSPB and JNCC, in association with WWT, with fieldwork conducted by volunteers.

\section{Authors' contributions}

KAW, JLN, GMH and ECR conceived and designed the study. KAW collected the data. KAW carried out the analyses. KAW, JLN, GMH and ECR wrote the manuscript. All authors read and approved the final manuscript.

Funding

This study was funded by the Peter Scott Trust for Education and Research in Conservation, Peter Smith Charitable Trust for Nature, Olive Herbert Charitable Trust, D'Oyly Carte Charitable Trust, N. Smith Charitable Settlement, Robert Kiln Charitable Trust, the estate of the late Professor Geoffrey Matthews OBE, and all who supported WWT's "Hope for Swans" Appeal.

\section{Availability of data and materials}

The datasets analysed during the current study are available from the corresponding author upon reasonable request.

\section{Declarations}

Ethics approval and consent to participate

The procedures employed in this study complied with the laws of the United Kingdom, where they were carried out.

Consent for publication

Not applicable.

Competing interests

The authors declare that they have no competing interests.

\section{Author details}

${ }^{1}$ Wildfowl \& Wetlands Trust, Slimbridge, Gloucestershire GL2 7BT, United Kingdom. ${ }^{2}$ Centre for Ecology and Conservation/Environment and Sustainability Institute, College of Life and Environmental Sciences, University of Exeter, Exeter TR10 9EZ, United Kingdom. ${ }^{3}$ Department of Zoology, University of Cambridge, Downing Street, Cambridge CB2 3EJ, United Kingdom.

Received: 12 February 2021 Accepted: 6 September 2021

Published online: 21 September 2021 


\section{References}

Altmann J. Observational study of behavior: sampling methods. Behaviour. 1974:49:227-67.

Amano T, Ushiyama K, Fujita G, Higuchi H. Alleviating grazing damage by white-fronted geese: an optimal foraging approach. J Appl Ecol. 2004;41:675-88.

Amat JA. Food usurpation by waterfowl and waders. Wildfowl. 1990;41:107-16. Arnold TW. Uninformative parameters and model selection using Akaike's Information Criterion. J Wild life Manage. 2010;74:1175-8.

Augst $\mathrm{H}-\mathrm{J}$, Hälterlein B, Fabricius K. From stopover to wintering: Bewick's Swans Cygnus columbianus bewickii in Schleswig-Holstein, northern Germany in winters 2016/2017 and 2017/2018. Wildfowl. 2019; Special Issue 5:139-63.

Bech C. Body temperature, metabolic rate, and insulation in winter and summer acclimatized Mute Swans (Cygnus olor). J Comp Physiol B. 1980;136:61-6.

Beekman J, Koffijberg K, Wahl J, Kowallik C, Hall C, Devos K, et al. Long-term population trends and shifts in distribution for Bewick's Swans Cygnus columbianus bewickii wintering in northwest Europe. Wildfowl. 2019; Special Issue 5:73-102.

BirdLife International. European Red List of Birds. Luxembourg: Office for Official Publications of the European Communities; 2015.

Black JM, Rees EC. The structure and behaviour of the Whooper Swan population wintering at Caerlaverock, Dumfries and Galloway, Scotland: an introductory study. Wildfowl. 1984;35:21-36.

Black JM, Carbone C, Wells RL, Owen M. Foraging dynamics in goose flocks: the cost of living on the edge. Anim Behav. 1992;44:41-50.

Brazil M. The whooper swan. London:T\&AD Poyser; 2003.

Brooks ME, Kristensen K, van Benthem KJ, Magnusson A, Berg CW, Nielsen A, et al. glmmTMB balances speed and flexibility among packages for zeroinflated generalized linear mixed modeling. R J. 2017;9:378-400.

Burnham KP, Anderson DR, Huyvaert KP. AIC model selection and multimodel inference in behavioral ecology: some background, observations, and comparisons. Behav Ecol Sociobiol. 2011;65:23-35.

Clausen KK, Clausen P, Fox AD, Fælled CC, Madsen J. Varying energetic costs of Brent Geese along a continuum from aquatic to agricultural habitats: the importance of habitat-specific energy expenditure. J Ornithol. 2013;154:155-62.

Crawley MJ. The R Book. 2nd ed. Chichester: Wiley; 2013

Davis JB, Guillemain M, Kaminski RM, Arzel C, Eadie JM, Rees EC. Habitat and resource use by waterfowl in the northern hemisphere in autumn and winter. Wildfowl. 2014; Special Issue 4:17-69.

Delm MM. Vigilance for predators: detection and dilution effects. Behav Ecol Sociobiol. 1990;26:337-42.

Dormann CF, Elith J, Bacher S, Buchmann C, Carl G, Carré G, et al. Collinearity: a review of methods to deal with it and a simulation study evaluating their performance. Ecography. 2013;36:27-46.

Drent RH, Fox AD, Stahl J. Travelling to Breed. J Ornithol. 2006;147:122-34.

Fox J, Weisberg S, Price B, Adler D, Bates D, Baud-Bovy G, et al. Car: companion to applied regression. R package version 3.0-2. 2018. https://cran.r-proje ct.org/package=car. Accessed 1 June 2021.

Friard O, Gamba M. BORIS: a free, versatile open-source event-logging software for video/audio coding and live observations. Method Ecol Evol. 2016:7:1325-30.

Frost TM, Austin GE, Calbrade NA, Mellan HJ, Hearn RD, Robinson AE, et al. Waterbirds in the UK 2017/18: The Wetland Bird Survey. Thetford: BTO, RSPB and JNCC, in association with WWT; 2019.

Gyimesi A, Stillman RA, Nolet BA. Cryptic interference competition in swans foraging on cryptic prey. Anim Behav. 2010;80:791-7.

Hall C, Crowe O, McElwaine G, Einarsson Ó, Calbrade N, Rees EC. Population size and breeding success of the Icelandic Whooper Swan Cygnus cygnus: results of the 2015 international census. Wildfowl. 2016;66:75-97.

Harrison XA, Donaldson L, Correa-Cano ME, Evans J, Fisher DN, Goodwin CED, et al. A brief introduction to mixed effects modelling and multi-model inference in ecology. PeerJ. 2018;6:e4794.

Hidding B, Nolet BA, Boer T, Vries PP, Klaassen M. Compensatory growth in an aquatic plant mediates exploitative competition between seasonally tied herbivores. Ecology. 2009;90:1891-9.

Hughes B, Green AJ. Feeding ecology. In: Kear J, editor. Ducks, geese and swans. Oxford: Oxford University Press; 2005. p. 27-56.
Jenssen BM, Ekker M, Bech C. Thermoregulation in winter-acclimatized common eiders (Somateria mollissima) in air and water. Can J Zool. 1989:67:669-73.

Keane EM, O'Halloran J. The behaviour of a wintering flock of Mute Swans Cygnus olor in southern Ireland. Wildfowl. 1992;43:12-9.

Kear J. Ducks, Geese and Swans. Oxford: Oxford University Press; 2005.

Kirby JS, Stattersfield AJ, Butchart SH, Evans MI, Grimmett RF, Jones VR, et al. Key conservation issues for migratory land-and waterbird species on the world's major flyways. Bird Conserv Int. 2008;18:S49-73.

Krivtsov SK, Mineyev YN. Daily time and energy budgets of Whooper Swans Cygnus cygnus and Bewick's Swans Cygnus bewickii in the breeding season. Wildfowl. 1991; Supplement No. 1:319-21.

Laubek B, Clausen P, Nilsson L, Wahl J, Wieloch M, Meissner W, et al. Whooper Swan Cygnus cygnus January population censuses for Northwest Mainland Europe, 1995-2015. Wildfowl. 2019; Special Issue 5:103-22.

Lüdecke D, Makowski D, Waggoner P, Patil I. Performance: assessment of regression models performance. $R$ package version 0.6.1. 2020. https:// cran.r-project.org/package=performance. Accessed 1 June 2021.

Metcalfe NB, Furness RW. Changing priorities: the effect of pre-migratory fattening on the trade-off between foraging and vigilance. Behav Ecol Sociobiol. 1984;15:203-6.

Nagy S, Petkov N, Rees EC, Solokha A, Hilton G, Beekman J, et al. International single species action plan for the conservation of the Northwest European population of Bewick's Swan (Cygnus columbianus bewickii). AEWA Technical Series No. 44. Bonn, Germany: AEWA; 2012.

Nakagawa S, Johnson PCD, Schielzeth $\mathrm{H}$. The coefficient of determination $R^{2}$ and intra-class correlation coefficient from generalized linear mixed-effects models revisited and expanded. J R Soc Interface. 2017:14:20170213.

Newth JL, Wood KA, McDonald RA, Nuno A, Semenov I, Chistyakov A, et al. Conservation implications of misidentification and killing of protected species. Conserv Sci Pract. 2019;1:e24.

Nisbet ICT. Bewick's Swans in the fenlands: the past and present status. Brit Birds. 1955;48:533-7.

Nolet BA, Drent RH. Bewick's Swans refuelling on pondweed tubers in the Dvina Bay (White Sea) during their spring migration: first come, first served. J Avian Biol. 1998;29:574-81.

Nolet BA, Bevan RM, Klaassen M, Langevoord O, van der Heijden YGJT. Habitat switching by Bewick's swans: maximization of average long-term energy gain? J Anim Ecol. 2002;71:979-93.

Nuijten RJM, Vriend SJG, Wood KA, Haitjema T, Rees EC, Jongejans E, et al. Apparent breeding success drives long-term population dynamics of a migratory swan. J Avian Biol. 2020a; 51: e02574.

Nuijten RJM, Wood KA, Haitjema T, Rees EC, Nolet BA. Concurrent shifts in wintering distribution and phenology in migratory swans: individual and generational effects. Global Change Biol. 2020b; 26: 4263-75.

Nuijten RJM, Prins EF, Lammer J, Mager C, Nolet BA. Calibrating tri-axial accelerometers for remote behavioural observations in Bewick's swans. J Zoo Aquar Res. 2020c; 8: 231-8.

Owen M, Cadbury CJ. The ecology and mortality of swans at the Ouse Washes, England. Wildfowl. 1975:26:31-42.

O'Donoghue PD, O'Halloran J. The behaviour of a wintering flock of whooper swans Cygnus cygnus at Rostellan Lake Cork. R Irish Acad Biol Environ. 1994;94:109-18.

O'Hare MT, Stillman RA, McDonnell JO, Wood LR. Effects of mute swan grazing on a keystone macrophyte. Freshwater Biol. 2007;52:2463-75.

Paulus SL. Time-activity budgets of non-breeding Anatidae: a review. In: Weller MW, editor. Waterfowl in winter. Minneapolis: University of Minnesota Press; 1988. p. 135-52

Ponting J. Factors affecting the feeding distribution of Bewick's (Cygnus columbianus bewickii) and Whooper (Cygnus cygnus) Swans wintering on the Ouse Washes, Norfolk. BSc. Thesis. Cardiff, UK: Cardiff University; 2014.

R Core Team. R: a language and environment for statistical computing. [3.6.3]. Vienna: R Foundation for Statistical Computing, 2020.

Rees EC. Bewick's Swan. London: T\&AD Poyser; 2006.

Rees EC, Kirby JS, Gilburn A. Site selection by swans wintering in Britain and Ireland; the importance of habitat and geographic location. Ibis. 1997:139:337-52. 
Rees EC, Bruce JH, White GT. Factors affecting the behavioural responses of whooper swans (Cygnus c. cygnus) to various human activities. Biol Conserv. 2005;121:369-82.

Rees EC, Cao L, Clausen P, Coleman JT, Cornely J, Einarsson O, et al. Conservation status of the world's swan populations, Cygnus sp. and Coscoroba sp.: a review of current trends and gaps in knowledge. Wildfowl. 2019; Special Issue 5:35-72.

Richards SA, Whittingham MJ, Stephens PA. Model selection and model averaging in behavioural ecology: the utility of the IT-AIC framework. Behav Ecol Sociobiol. 2011;65:77-89.

Robinson RA, Sutherland WJ. Post-war changes in arable farming and biodiversity in Great Britain. J Appl Ecol. 2002;39:157-76.

Tatu KS, Anderson JT, Hindman LJ, Seidel G. Diurnal foraging activities of Mute Swans in Chesapeake Bay, Maryland. Waterbirds. 2007;30:121-8.

Thomas GJ, Allen DA, Grose MPB. The demography and flora of the Ouse Washes, England. Biol Conserv. 1981;21:197-229.

Warton DI, Hui FK. The arcsine is asinine: the analysis of proportions in ecology. Ecology. 2011:92:3-10.

Wickham H, Seidel D. Scales: scale functions for visualization. R package version 1.1.1. 2020. https://cran.r-project.org/package=scales. Accessed 1 June 2021.

Włodarczyk R. The daily activity pattern in males and females of the Mute Swan (Cygnus olor, Anseriformes) during different parts of the breeding season. North-Western J Zool. 2017;13:85-93.

Włodarczyk R, Minias P. Division of parental duties confirms a need for biparental care in a precocial bird, the mute swan Cygnus olor. Anim Biol. 2015;65:163-76.

Wood KA, Włodarczyk R. Cygnus olor Mute Swan. In: Keller V, Herrando S, Voříšek P, Franch M, Kipson M, Milanesi P, et al., editors. European breeding bird atlas 2: distribution, abundance and change. Barcelona: European Bird Census Council \& Lynx Edicions; 2020. p. 100-1.

Wood KA, Ponting J, D'Costa N, Newth JL, Rose PE, Glazov P, et al. Understanding intrinsic and extrinsic drivers of aggressive behaviour in waterbird assemblages: a meta-analysis. Anim Behav. 2017;126:209-16.

Wood KA, Nuijten RJM, Newth JL, Haitjema T, Vangeluwe D, loannidis P, et al. Apparent survival of an Arctic-breeding migratory bird over 44 years of fluctuating population size. Ibis. 2018;160:413-30.

Wood KA, Brown MJ, Cromie RL, Hilton GM, Mackenzie C, Newth JL, et al. Regulation of lead fishing weights results in mute swan population recovery. Biol Conserv. 2019a;230:67-74.

Wood KA, Hilton GM, Newth JL, Rees EC. Seasonal variation in energy gain explains patterns of resource use by avian herbivores in an agricultural landscape: insights from a mechanistic model. Ecol Model. 2019b;409:108762.

Wood KA, Newth JL, Brides K, Burdekin M, Harrison AL, Heaven S, et al. Are long-term trends in Bewick's Swan (Cygnus columbianus bewickii) numbers driven by changes in winter food resources? Bird Conserv Int. 2019c;29:479-96.

Wood KA, Ham P, Scales J, Wyeth E, Rose PE. Aggressive behavioural interactions between swans (Cygnus spp.) and other waterbirds during winter: a webcam-based study. Avian Res. 2020;11:30.

Wood KA, Stillman RA, Newth JL, Nuijten RJM, Hilton GM, Nolet BA, et al. Predicting avian herbivore responses to changing food availability and competition. Ecol Model. 2021;441:109421.

Zar JH. Standard metabolism comparisons between orders of birds. Condor. 1968;70:278.
Ready to submit your research? Choose BMC and benefit from:

- fast, convenient online submission

- thorough peer review by experienced researchers in your field

- rapid publication on acceptance

- support for research data, including large and complex data types

- gold Open Access which fosters wider collaboration and increased citations

- maximum visibility for your research: over 100M website views per year

At BMC, research is always in progress.

Learn more biomedcentral.com/submissions 